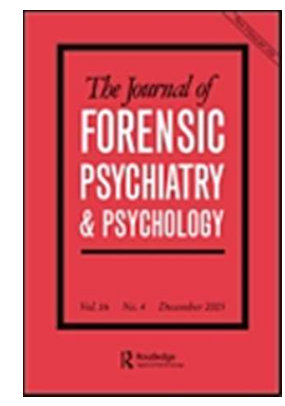

\title{
Are validation scales useful for Detecting Deliberately Faked Personality Tests? A study in incarcerated populations.
}

\begin{tabular}{|r|l|}
\hline Journal: & Journal of Forensic Psychiatry and Psychology \\
\hline Manuscript ID: & RJFP-2011-0106.R1 \\
\hline Manuscript Type: & Regular Article \\
\hline Keywords: & fake-bad, assessment, prisoners \\
\hline \multicolumn{2}{l}{} \\
\hline
\end{tabular}

SCHOLARONE ${ }^{\text {m }}$

Manuscripts 


\title{
Are validation scales useful for Detecting Deliberately Faked Personality Tests? A study in incarcerated populations.
}

\begin{abstract}
Personality self-report questionnaires are frequently used in forensic settings to detect psychopathology, to predict recidivism, and to assess adaptability to life in prison. Although most personality questionnaires include validity or control scales, even with the scales most outcomes can be easily manipulated. The aim of this study is to analyze the utility of the control scales of the Situational Personality Questionnaire. A sample of 200 male prisoners was randomized into two groups. Both groups completed the SPQ as a part of the mandatory psychological assessment when they entered prison, and then again 8 months later. In time 2, one group received instructions to falsify the results of the questionnaire. Results indicated that the feigned induction was effective. The control scales were not able to detect feigners. Results are discussed with regard to their implications for further research into assessing fake responses in forensic settings.
\end{abstract}

Keywords: fake-bad; assessment; prisoners.

Word count $=4812$ 
The use of personality self-report questionnaires is very common in forensic settings. These scales are usually employed to detect the presence of psychopathology, especially personality disorders or psychopathic traits, to predict recidivism, or to predict adaptability to prison life (Listwan, Van Voorhis, \& Ritchey, 2007). The findings from these personality tests are then used as forensic evidence in correctional and judicial settings to help determine the subject's (1) competence, (2) criminal responsibility, and/or (3) level of risk (Duellman \& Bowers, 2004).

Although different types of interviews are also frequently used for these purposes, questionnaires are generally considered as providing "objective" information that is uninfluenced by the beliefs, judgments and experiences of the interviewer. However, personality questionnaires, as with all self-reports, are susceptible to their answers' being manipulated in distorted, biased, or false ways. There is a variety of possible distortions, one of them being respondents' attempts to present favorable or unfavorable pictures of themselves, yielding inaccurate and misleading personality profiles. In some cases, respondents actually believe in their positive self-reports, but in other cases, respondents consciously dissemble, especially under public conditions (Paulhus, 1984). In some situations, individuals can be motivated to distort their personality scores or to exaggerate psychopathological problems in order to obtain beneficial outcomes, and therefore the effect of this distortion on self-reports should be controlled for.

Despite efforts to design reliable and valid instruments for assessing personality traits and dispositions, questionnaires remain vulnerable to lying, faking, feigning, and malingering (Sullivan \& King, 2010). There are different types of faking, and the more common distinction has been done between "fake good" and "fake bad". "Fake good" has been defined as a "conscious effort to manipulate responses to personality items to make a positive impression" (Zickar \& Robie, 1999). This bias is expressed as intentionally looking better than one might perform, and it is probably the most extensively studied bias (Mersman \& Schultz, 1998). "Fake bad" is expressed as intentionally looking worse than one might perform, and it has been also studied, mainly focused on the malingering of 
psychopathology ${ }^{1}$ (Sullivan \& King, 2010). As Meehl and Hathaway (1946) pointed out, "one of the most important failings of almost all structured personality tests is their susceptibility to 'faking' and 'lying' in one way or another" (p. 525). However, occurrence of this bias may vary in different contexts and different populations.

In forensic settings, the question of faking is of primary concern (Pierson, Rosenfeld, Green \& Belfi, 2011), particularly where the outcome of the assessment influences the legal status of prisoners, who may exaggerate various psychological problems in an effort to receive special services (e.g., psychopharmacological agents) or who may minimize their involvement in drug or alcohol use to avoid more stringent probationary terms and requirements (Morey \& Quigley, 2002). Thus, the reliability of the assessment may be severely compromised when attempts to feign go undetected (Rogers, 1997). As a result, psychologists have been involved in detecting deception during psychological evaluations in legal contexts. To control for faking, validity scales have been usually included to assess the accuracy of self-reports (Mogge, Lepage, Bell \& Ragatz, 2009; Morey, 1991; Schoenberg, Dorr \& Morgan, 2006). Literature about validity scales has been large (Rogers, Sewell, Martin \& Vitacco, 2003; Singh, Avasthi \& Grover, 2007), and aimed at constructing robust control strategies for detecting feigners. However, researchers recognize that it is still relatively easy to deliberately exaggerate the results without been detected (Piedmont, McCrae, Riemann, \& Angleitner, 2000; Singh et al., 2007). Many researchers have come to recognize the limitations of validity scales, and even several test authors (for instance NEO-PI-R authors) expressly omit the usual validity scales because they believe there is scarce empirical justification for their use (Piedmont et al., 2000).

The typical design for the study of feigning has been the "faking paradigm" (Piedmont et al., 2000) in which participants are explicitly asked to simulate some form of distortion (fake good or fake bad) (Mogge et al., 2009; Shores \& Carstairs, 1998). The scores of these "fakers" are then compared to those of control groups. These experiments have been useful 
for studying the effectiveness of control scales. Several studies have shown that validity scales distinguish between faking and control conditions, and it has been concluded that they are able to detect the bias in question (Baity, Siefert, Chambers \& Blais, 2007; Piedmont et al., 2000). However, most of these studies have been done in the context of personnel selection or with volunteer undergraduate students (Omar \& Uribe, 2000) rather than in clinical or prison settings, and they are often criticized as generalizing the results to other contexts. Regarding students, Heinze and Vess (2005) pointed out that the incentive to fake in real-world situations (such as when one is evading criminal prosecution) is much stronger than an experimental context can ethically assess. Regarding personnel selection, several researchers have claimed that faking is used by relatively few applicants and should therefore not be an important issue in this context (Griffin, Hesketh,\& Grayson, 2004; Hough, 1998). In this point, it should be emphasized that sensitivity and specificity of a test to detect distortion and faking depends on the base rate of invalid responding in the sample. Sensitivity reflects the capacity of an instrument to yield true positive results, whereas specificity reflects the capacity of an instrument to yield true negative results. Both sensitivity and specificity are determined by the established cutting score of the test, but cutting scores vary for different populations For example, Lim and Butcher (1996) showed that a cutoff score that discriminated faking bad from honest student respondents with $100 \%$ accuracy identified fully $30 \%$ of a sample of presumably honest psychiatric patients as faking bad. These results point the importance of base rate information in understanding the accuracy of prediction methods to detect feigning, and suggest that different cutoff scores should be used for different populations In addition; limitations also come from the problem of false positives. For example, Lim and Butcher (1996) showed that a cutoff score that discriminated faking from honest student respondents with $100 \%$ accuracy identified fully $30 \%$ of a sample of presumably honest psychiatric patients as faking bad. These results suggest that different cutoff scores should be used for different populations. These results point the importance of base rate information in understanding the accuracy of 
prediction methods to detect feigning, and suggest that different cutoff scores should be used for different populations

Another option for discerning faking is to compare self-report scores with independent assessments such as observer ratings. Piedmont et al.(2000) concluded the questionnaires are not an infallible method, and furthermore the validity scales will not improve them. They propose to use well-validated instruments with improved quality and multiple sources of data, like external criteria, separate instruments or independent sources

Yet another strategy to detect fakers involves using multivariate techniques such as discriminant factorial analysis (Cashel, Rogers, Sewell, \& Martin-Cannici, 1995; Schoenberg et al., 2006). In this line, Rogers, Harrell, and Liff (1993) have developed the Rogers Discriminant Function scale (RDF) (Rogers, Sewell, Morey, \& Ustad, 1996) for the Personality Assessment Inventory (PAI, Morey, 1991).This function distinguishes between malingering and non-malingering simulators (Rogers et al., 1996) and has demonstrated an impressive effectiveness across several simulation samples (Hopwood, Morey, Rogers \& Sewell, 2007; Sullivan \& King 2010). However, the use of RDF in criminal forensic settings is being increasingly questioned (Hopwood et al., 2007). Rogers et al. (1998) applied the RDF to a forensic sample and found that the detection accuracy was near chance levels, leading these authors to issue a caution against using the RDF with forensic populations. Kucharski, Toomey, Fila, and Duncan (2007) also found that the RDF scale and the MAL index from PAI do not have acceptable enough sensitivity and specificity to differentiate the malingering from the non-malingering in a sample of criminal defendants. Negative results with the RDF may occur because the base rate of pathology-free individuals may be lower in forensic populations than in standard simulation studies (Hopwood et al., 2007).

Overall, the use of control scales and other associated solutions to the problems of malingering has received significant empirical attention in the general population, but there few studies respecting the validity of the control scales when used with incarcerated populations. As mentioned above, malingering is a very relevant topic given the characteristics of incarcerated populations. The aim of this study is to investigate the effect 
a malingering induction has on each of the scales of a personality questionnaire and to measure the utility of the control scales in detecting faking in an experimental induction with an incarcerated sample. For this study, the Situational Personality Questionnaire (CPS; Fernández-Seara et al., 1998) has been used because it is a common tool used to assess personality traits in Spanish forensic settings, and it is a mandatory instrument in the assessment protocol in the prison where the present study was conducted.

\section{Method}

\section{Participants}

The respondents were 200 male prisoners from the Tarragona (Spain) prison, with an age of 34 (9.2). The only exclusion criterion was a low level of reading; subjects were excluded when their reading level was insufficient to understanding the sentences of the questionnaire. The sample was randomized into two groups, Control Group (CG) and Feigner Group (FG), with 100 participants in each. The average age was 34.6 (9) years for CG, and 33.4 (9.4) years for FG. The average duration of incarceration (in weeks) was 24.9 $(S D=34.6)$ for the $C G$ and $34.5(S D=40.8)$ for the $F G$. In terms of educational attainment among CG participants, 35\% subjects completed primary school, 61.2\% completed secondary school, and 3.8\% completed university studies. Among FG participants, $41.5 \%$ subjects completed primary school, $57.1 \%$ completed secondary school, and $1.3 \%$ completed university studies. For all categories (age, length of incarceration, and education level) there were no significant differences between CG and FG.

\section{Instruments.}

Situational Personality Questionnaire (CPS; Fernández-Seara et al., 1998). This questionnaire contains 233 items, each with two answer options (true/false), and requires approximately thirty minutes to be completed. This instrument offers scores on 15 personality scales, 3 control scales and 5 summary scales (second order factors). The 15 
main scales are: Emotional Stability (irritable, susceptible, and overexcited versus serene, stable, and balanced), Anxiety (relaxed, calm, and patient versus worried, anxious, and fearful), Self-Concept(having low self-esteem and poor self-image versus having high self-esteem and strong self-image), Efficacy (socially insecure, with social concerns versus competent, with social initiatives), Self-Confidence(hesitant and insecure versus trusting and confident about him/herself and his/her possibilities),Independency (dependent versus autonomous), Dominancy (docile, obedient, and trying to please versus energetic, assertive, organizing, and competitive) Cognitive Control (external attribution and impulsive versus cautious, analytical, and calculating), Sociability (reserved, withdrawn, shy, and distant versus friendly, sociable, enthusiastic, expressive, and participative), Social Adjustment (rebellious and in conflict with the rules versus socialized, dutiful, and accepting of the rules), Aggressiveness (peaceful and unperturbed versus warlike and critical), Tolerance (unyielding, rigid, dogmatic, and "picky" versus understanding, permissive, flexible, and open), Social intelligence (socially awkward and change-avoidant versus socially comfortable and flexible with change), Integrity/ Honesty (informal and undisciplined versus reliable, responsible, formal, and disciplined), and Leadership (uninterested in giving orders or leading others versus confident in organizing tasks or leading people).

The 5 summary scales are: Adjustment (undecided, tense, capable, critical, doubtful versus balanced, relaxed, understanding, sure), Leadership (tolerant and permissive versus assertive and competitive), Independency (Submissive, doubtful, tolerant, and conventional versus autonomous, rebellious, and self-confident), and Consensus (rule-conflictive, insecure, and impulsive versus reliable, socially skillful, and organized).

The CPS incorporates three validity scales that are used to detect purposeful distortion: The Sincerity Scale is composed of 21 items referring to behaviors that social norms advise against carrying out. A low score (lower than 5) refers to a person who desires to hide personal defects. A high score (higher than 9) refers to a person who is sincere and truthful. 
The Social Desirability Scale is composed of 28 items assessing the distortion that can be introduced into the responses by overestimation of oneself and one's own behavior. A low score (lower than 24) on this factor refers to a person whose social self-conception corresponds to natural and spontaneous behavior. A high score (higher that 27) refers to a person who ruminates and worries about his/her social image. The Response Control Scale is composed of 26 items, grouped in 13 pairs with similar answer direction, and it is expected that responders answer both items similarly. The objective of this scale is to detect individuals who respond the questionnaire carelessly, without attending to the items. A score of 8 or higher means coherency in the answering. A score of 7 or lower indicates incoherency, meaning that the evaluation results should be considered with caution.

Strengths of this instrument include its broad understandability, due to its simple language, its validation using a large Spanish sample $(n=39,631)$, and its standing, established through previous research, as a good instrument to predict conflict-seeking prisoners (Raya, Eliseo \& Medina, 2008).

Procedure

All participants filled out the CPS as part of a mandatory psychological assessment when entering prison (time 1). After a period of approximately eight months (time 2), participants were asked to fill out the questionnaire again $(X=251.6$ days for the $C G$, and $X=251.2$ days for $F G$ ). There were no significant differences between groups in the time spent between time 1 and time $2(t=0.99)$.

In time 2, the FG group received instructions to fake the results of the questionnaire, thereby presenting a different self-image; it was not specified to fake good or bad. FG participants were told that they would receive a small reward for the task (cigarettes, sweets, chocolate, etc.) if their new scores different from their initial test scores at time 1, and if the test did not detect that they were faking. At the end of the experiment, all participants received the reward independent of the results. The specific instructions were made in colloquial language, were always the same, and were meant to induce participants 
to fake the questionnaire in such a way that the test did not detect the deception. The CG group received the same standard test instructions that they received in time 1.

Results

Differences between groups and times

A $2 \times 2$ ANOVA (FG vs. CG $\times$ time 1 vs. time 2) analysis with Sidak's post-hoc tests were applied. The aim of this analysis was to analyze the efficacy of the fake induction across the analysis of the differences according groups (FG vs. CG) in each of the scales, before and after the fake induction. The descriptive data are shown in Table 1.

Insert table 1

ANOVAs results are shown in Table 2. Regarding group effects and time effects, significant differences have been found for almost all the scales. That is, there were differences between both groups (FG and CG), and scores changed from Time 1 to Time 2 . In order to analyze groups differences Sidak's post hoc analysis between groups (FG vs. CG) were applied for both times (Time 1 and 2), Although groups were randomized, in time 1 there were significant differences in Dominance $(0=.03)$, Independence $(p=.03)$, Social Adjustment; $(p=.02)$, Aggressiveness $(p<.01)$, and Tolerance, $(p<.05)$ scales. In time 2, after the fake induction, there were significant differences between both groups in almost all of the scales (Emotional Stability, $p<.001$; Efficacy, $p<.001$; Self-Confidence, $p<.001$, Dominance, $\quad \mathrm{p}<.01 ; \quad$ Independence, $\quad \mathrm{p}<.01$; Cognitive Control, $\mathrm{p}=<.01$; Sociability, $\mathrm{p}<.001$; Social Adjustment, $\mathrm{p}<.01$; Aggressiveness, $\mathrm{p}<.01$; Tolerance, $\mathrm{p}<.01$; Social Intelligence, $\mathrm{p}<.01$; Integrity/honesty, $\mathrm{p}<.01$; Leadership, $\mathrm{p}<.01$; Sincerity, $\mathrm{p}<.01$, Social Desirability, $p<.01 ;$ Response Control, $p<.01)$. There were no significant differences between groups in time 2 except in Self-concept and Anxiety scales. 
More important, results showed significant interaction effects (group x time) for almost all the scales (see Table 2; Graphic 1), except for the Anxiety, Independence, and Sincerity scales. In order to analyze these interaction effects Sidak's post hoc analysis between time 1 and 2 were applied for both groups. For the CG group, there were no differences between time 1 and 2 for any scale. However, for the FG group, there were significant differences in all the scales (Emotional Stability, $p<.005$; Anxiety, $p<.005$; Self-concept, $p<.05$; Efficacy, $p<.001$; Self Confidence, $p<.001$; Dominance, $p=.040$; Independence, $p=.040$; Cognitive Control, $p<.01$; Sociability; $p<.01 ;$ Social Adjustment, $p<.01 ;$ Aggressiveness, $p<.01$; Tolerance, $\mathrm{p}<.01$; Social Intelligence, $\mathrm{p}<.01$; Integrity/Honesty, $\mathrm{p}<.01$; Leadership, $\mathrm{p}<.01$; Sincerity, $p<.01$; Social Desirability, $p<.01$; Response Control, $p<.05)$.

Insert Graphic 1

Insert table 2

\section{Classification of the participants' as "reliable" respondents}

Normative data of CPS in the Spanish sample allow for the categorizing of respondents as "reliable" in function of the three control scale sores (Fernández-Seara et al., 1998). According to the cutoff scores, in time 1, the percentage of the sample that could be categorized as "reliable" was between $60.5 \%$ and $97.5 \%$ (see Table 3). In time 2, after the experimental induction, the percentages remain similar in both groups, FG and CG. In fact, the percentage of FG participants categorized as "reliable" increased in the Response Control scale by more than $10 \%$.

According to normative data (Fernández-Seara et al, 1998), average scores in control scales (see Table 1) indicated that participants were not dishonest and did not hide personal defects, as mean scores on Sincerity were higher than 5 . These scores increased 
in time 2, where FG participants scored higher than 9, meaning that they were assumed to be highly "sincere". Regarding Social Desirability, all average scores were lower than 24, indicating that participants were "natural and spontaneous in their social image", and FG participants even showed better scores in Time 2. Finally, Response Control scores were higher than 8, meaning that participants' answers were reliable and coherent.

Insert table 3

\section{Discussion}

The present study was aimed at analyzing the efficacy of control scales at detecting faking in a commonly used personality questionnaire (CPS) administered in a Spanish prison. For that purpose, an experimental "fake" induction was used, and the subsequent data were compared to a control group. In general, results from this study do not support the utility of validity scales for the CPS questionnaire.

First, results indicated that "fake" induction was successful, as FG participants changed their scores in all scales after the induction. Data did not show differences between time 1 and 2 for the control (CG) group, indicating that participants' scores remain relatively stable after 8 months. This result was expected since the questionnaire measures stable dispositions and good test-retest reliability data have been reported (Fernández-Seara et al., 1998). However, FG group did show differences for every subscale, meaning that their scores changed in time 2 when faking was requested. Furthermore, group $\mathrm{x}$ time interaction effects were significant for almost all scales, indicating that changes were bigger for FG than for CG group. Only two personality scales did not show significant interaction effects: Anxiety and Independence. Anxiety scores were lower in time 2 for all participants (although post analysis showed only significant differences for FG), and Independence scores were higher in time 2 for all participants (although again post analysis showed only 
significant differences for FG). It is possible that anxiety and independence have positive social values in prison contexts, making high independence and low anxiety highly valued traits among prisoners. In this sense, these dimensions might be more easily affected by unconscious, self-deceptive enhancement (Paulhus, 1984).

Regarding the efficacy of validity scales in detecting respondents' attempts to manipulate the answers, the results did not support their utility. According to normative data (Fernández-Seara, et al., 1998), after fake induction, $90.1 \%$ of FG participants were sincere, $96.3 \%$ showed a natural and spontaneous self-image and $71.6 \%$ answered the questionnaire with interest and attention, avoiding answering at random. Taking average scores into consideration, FG participants were even more "sincere" and "natural and spontaneous in their social image" in Time 2 than in Time 1. These data clearly point out that the control scales were not able to detect the feign manipulation.

Several limitations of the present study should be noted. First, the current population was exclusively male. Future studies might question whether these results are applicable to females. Second, faking instructions did not direct the faking into "good" or "bad" orientation. Further research should be address to distinguish between fake good and fake bad inductions, in order to explore different characteristics related to the direction of the faking. Another limitation is the specific personality questionnaire used. As mentioned, it is the most common personality instrument used in Spanish forensic settings, but it is only available in the Spanish language, so it is not possible to compare the present results with those from other countries, and to determine the degree to which the findings of the study are generalizable to other particular measures.

Finally and surprisingly, there were significant differences between groups in time 1 in some factors, Compared to CG participants, FG participants showed higher scores in Dominance, Independence, and Aggressiveness and lower scores in Social Adjustment, and Tolerance. This was not expected since the sample was randomized and there were no differences with respect to age, length of incarceration, and educational level. 
Despite these limitations, the design of this study is unique in that a fake induction was issued among an incarcerated population; traditionally faking and malingering has been studied in a context of personnel selection or with volunteer undergraduate students. The present study has notable implications for future research and for the usage of validity scales in forensic contexts, because in those situations individuals are motivated to distort their personality scores or to exaggerate psychopathological problems in order to obtain beneficial outcomes. The setting studied in this work is one of these possible situations, as prisoners may have multiple motivations for feigning.

In conclusion, results indicate that validity scales are not effective tools to detect feigning in a jailed sample, although, as previously mentioned, findings of the present study are not generalizable to other particular measures. It should be highlighted that psychological testing is one of several strategies used in forensic decision-making, but it is not the only source used to answer forensic questions. Evaluation also includes other strategies (observation, interviews, etc.) and collateral information. Personality questionnaires remain very useful assessment procedures in forensic questions, but it is important to know the relative vulnerability of these personality measures to being feigned. More study is needed to establish systems that are truly effective at detecting insincerity, and to design new ways of controlling feigning. One alternative entails using a combination of relevant scales grouped in one factor, rather than using additional scales that can be easy to detect and to circumvent by participants (Schoenberg et al., 2006). These topics are fundamental when the assessment is done in a context associated with higher feigning prevalence. 


\section{References}

American Psychiatric Association (APA). Diagnostic and Statistical manual of mental disorders, text revision. 4th ed. Washington, DC: APA; 2000.

Baity, M.R., Siefert, C.J., Chambers, A., \& Blais, M.A. (2007). Deceptiveness on the PAl: A Study of Naïve Faking With Psychiatric Inpatients. Journal of Personality Assessment, 88, 16-24.

Cashel, M.I., Rogers, R., Sewell, K.S., \& Martin-Cannici, C. (1995). The personality Assessment Inventory (PAI) and the detection of defensiveness. Assessment, 2, 333342.

Duellman, R.M., \& Bowers, T.G. (2004). Use of personality assessment inventory (PAI) in forensic correctional settings: evidence for concurrent validity. International Journal of Forensic Psychology, 1, 42-57.

Fernández-Seara,J.L., Seisdedos, N., \& Mielgo, M. (1998). CPS, Cuestionario de Personalidad Situacional. TEA Ediciones. Madrid.

Griffin, B., Hesketh, B., \& Grayson, D. (2004). Applicants faking good: evidence of item bias in the NEO PI-R. Personality and Individual Differences, 36, 1545-1558.

Heinze, M.C. \& Vess, J. (2005). The Relationship Among Malingering, Psychopathy, and the MMPI-2 Validity Scales in Maximum Security Forensic Psychiatric Inpatients. Journal of Forensic Psychology Practice, 5, 35- 53

Hopwood, C. J., Morey, L. C., Rogers, R., \& Sewell, K. (2007). Malingering on the Personality Assessment Inventory: Identification of Specific Feigned Disorders. Journal of Personality Assessment, 88, 43 - 48.

Hough, I.M. (1998). Effects of intentional distortion in personality measurement and evaluation of suggested palliatives. Human Performance, 11, 209-244.

Kucharski, L.T., Toomey, J.P., Fila, K. \& Duncan, S. (2007). Detection of Malingering of Psychiatric Disorder with the Personality Assessment Inventory: An Investigation of Criminal Defendants. Journal of Personality Assessment, 88, 25-32. 
Lewis, J. L., Simcox, A. M., \& Berry, D. T. (2002). Screening for feigned psychiatric symptoms in a forensic sample using the MMPI-2 and the Structured Inventory of Malingered Symptomatology. Psychological Assessment, 14, 170-176.

Lim, J., \& Butcher, J.N. (1996). Detection of faking bad on the MMPI-2: Differentiation among faking-bad, denial, and claiming extreme virtue. Journal of Personality Assessment, 67, 1-25.

Listwan, S.J., Van Voorhis, P., \& Ritchey, P.N. (2007). Personality, Criminal Behavior, and Risk Assessment. Criminal Justice and Behavior, 34, 60 -75.

Meehl, P.E., \& Hathaway, S.R. (1946). The K factor as a suppressor variable in the Minnesota Multiphasic Personality Inventory. Journal of Applied Psychology, 30, 525564.

Mersman, J.L., \& Shultz, K.S. (1998). Individual differences in the ability to fake on personality measures. Personality and Individual Differences, 24(2), 217-227.

Mogge, N.L., Lepage, J.S., Bell, T., \& Ragatz, L. (2009). The negative distortion scale: a new PAI validity scale. Journal of Forensic Psychiatry \& Psychology, 21, 77-90.

Morey, L. (1991). Professional manual for the Personality Assessment Inventory. Odessa, FL: Psychological Assessment Resources.

Morey, L.C., \& Quigley, B.D. (2002). The use of the Personality Assessment Inventory in assessing offenders. International Journal of Offender Therapy and Comparative Criminology, 46, 333-349.

Norris, M. P., \& May, M. C. (1998). Screening for malingering in a correctional setting. Law and Human Behavior, 22, 315-323.

Omar, A., \& Uribe, H. (2000) Tendencia al falseamiento y temor a ser descubierto [Tendency to distortion and fear of discovery]. Acta Psiquiátrica y Psicológica de América Latina, 46, 67-73.

Paulhus, D.L. (1984). Two-component models of socially desirable responding. Journal of Personality and Social Psychology, 46, 598-609. 
Piedmont, R.L., McCrae, R.R., Riemann, R., \& Angleitner, A. (2000). On Invalidity of Validity Scales: Evidence from Self-reports and Observer Rating in volunteer Samples. Journal of Personality and Social Psychology, 78, 582-593.

Pierson, A. M., Rosenfeld, B., Green, D., \& Belfi, B. (2011). Investigating the Relationship between Antisocial Personality Disorder and Malingering. Criminal Justice and Behavior, 38, $146-156$.

Raya, D., Eliseo, A., \& Medina, P. (2008). Validació creuada en població penitenciaria de criteris psicomètrics i tècnics per la predicció de conductes adaptatives i factors de risc [Cross validation of psychometric and technical criteria to predict adaptive behaviour and risk factors in jailed population]. Centre d'estudis jurídics i formació $\begin{array}{lll}\text { especialitzada. } & \text { Retrieved }\end{array}$ http://www20.gencat.cat/docs/Justicia/Documents/ARXIUS/SC-3-152-08.pdf Barcelona.

Rogers, R. (1997). Current status of clinical methods. In R. Rogers (Ed.), Clinical assessment of malingering and deception. New York: Guilford.

Rogers, R., \& Correa, A.A. (2008) Determinations of Malingering: Evolution from CaseBased methods to detection strategies. Psychiatry, Psychology and Law, 15, 213223.

Rogers, R., Harrell, E.H., \& Liff, C.D. (1993). Feigning neuropsychological impairment: A critical review of methodological and clinical considerations. Clinical Psychology Review, 13, 255-274.

Rogers, R., Sewell, K.W., Martin, M. A., \& Vitacco, M.J. (2003). Detection of feigned mental disorders: a meta-analysis of the MMPI-2 and malingering. Assessment, 10, 60- 77.

Rogers, R., Sewell, K., Morey, L., \& Ustad, K. (1996). Detection of feigned mental disorders on the Personality Assess Inventory: a discriminant analysis. Journal of Personality Assessment, 67, 629 - 640. 
Rogers, R., Sewell, K.W., Cruise, K.R., Wang, E.W., \& Ustad, K.L. (1998). The PAI and feigning: A cautionary note on its use in forensic-correctional settings. Assessment, 5 , $399-405$.

Schoenberg, M.R., Dorr, D., \& Morgan, C.D. (2006). Development of discriminant function to detect dissimulation for the Millon clinical Multiaxial Inventory ( $3^{\text {rd }}$ edition). The journal of Forensic Psychiatry \& Psychology, 17, 405-416.

Shores, A., \& Carstairs, J. R. (1998). Accuracy of the MMPI-2 computerized Minnesota Report in identifying fake-good and fake-bad response sets. The Clinical Neuropsychologist, 12, 101-106.

Singh, J., Avasthi, A., \& Grover, S. (2007). Malingering of Psychiatric disorders: a review. German Journal of Psychiatry, 10, 126-132.

Sullivan, K., \& King, J. (2010). Detecting faked psychopathology: A comparison of two tests to detect malingered psychopathology using a simulation design. Psychiatry research, $176,75-81$.

Zickar, M.J., \& Robie, C. (1999). Modeling faking good on personality items: An item-level analysis. Journal of Applied Psychology, 84, 551-563.

\section{Acknowledgements}

CIBERobn is an initiative of ISCIII. This study has been supported in part by the Ministerio de Ciencia e Innovación (Plan Nacional de Investigación Científica, Desarrollo e Innovación Tecnológica 2008-2011) in the project (PSI2008-04392/PSIC). 
Footnote.

${ }^{1}$ Although both "malingering" and feigning" are use in this paper, there are differences between the terms. Malingering is defined as the intentional production of false or grossly exaggerated physical or psychological symptoms, motivated by external incentives such as avoiding military duty, avoiding work, obtaining principal compensation, evading criminal prosecution or obtaining drugs (APA, 2000). Feigning means to deliberately fabricate or to grossly exaggerate a clinical condition. Psychological tests can be used to assess whether an individual may be feigning but tests cannot establish the motivations required to categorize such deception as malingering (Rogers\& Correa, 2008). 
1

2

3

4

5

7

8

9

10

11

12

13

14

15

16

17

18

19

20

21

22

23

Table 1. Descriptives before and after the fake induction

\begin{tabular}{|c|c|c|c|c|c|c|c|c|}
\hline & \multicolumn{4}{|c|}{ Time 1} & \multicolumn{4}{|c|}{ Time 2} \\
\hline & \multicolumn{2}{|c|}{$F G$} & \multicolumn{2}{|c|}{ CG } & \multicolumn{2}{|c|}{$F G$} & \multicolumn{2}{|c|}{ CG } \\
\hline & $M$ & SD & $\mathrm{M}$ & SD & $\mathrm{M}$ & SD & $\mathrm{M}$ & SD \\
\hline E stab & 13.6 & 5.7 & 13.6 & 5.4 & 12.1 & 5.6 & 14.8 & 5.7 \\
\hline Anx & 14.3 & 5.3 & 15 & 5.2 & 12.7 & 4.9 & 13.9 & 5.6 \\
\hline S-con & 15.9 & 4.3 & 15.1 & 4 & 13.1 & 5.2 & 16.3 & 4.1 \\
\hline Effi & 18.9 & 4.1 & 19.1 & 3.5 & 11.4 & 6.1 & 19.6 & 3.7 \\
\hline S-conf & 16.7 & 4.7 & 16.3 & 4.2 & 11.7 & 5.3 & 17.4 & 4.2 \\
\hline Indep & 9.6 & 3.5 & 8.6 & 3.3 & 10.5 & 3.3 & 9.1 & 3.5 \\
\hline Dom & 9.7 & 4.8 & 8.2 & 4.2 & 14.7 & 5.5 & 8.2 & 4.4 \\
\hline Cog & 16.6 & 3.9 & 17.5 & 3.2 & 9.9 & 5.4 & 18.6 & 3.4 \\
\hline Sociab & 15.2 & 5.5 & 15.5 & 5.1 & 12 & 4.9 & 15.8 & 5 \\
\hline S adj & 12 & 3.5 & 13.1 & 3.3 & 8.5 & 4 & 12.8 & 3.1 \\
\hline Aggre & 9.2 & 5.8 & 6.9 & 5.4 & 12.8 & 6.1 & 7.7 & 5.7 \\
\hline Tol & 12.3 & 4.3 & 13.7 & 3.6 & 9.9 & 5.4 & 18.6 & 3.4 \\
\hline S Intel & 15.4 & 2.9 & 20.1 & 3.7 & 8.7 & 4.7 & 16.1 & 3 \\
\hline $\begin{array}{l}\text { Int/Ho } \\
n\end{array}$ & 20.8 & 2.8 & 8.9 & 3.6 & 10.8 & 6.4 & 21.1 & 2.8 \\
\hline Lead & 8.9 & 3.6 & 8.2 & 3 & 11.3 & 4.3 & 7.9 & 3.4 \\
\hline Sinc & 8.6 & 4 & 7.9 & 3.1 & 12.2 & 3.6 & 7.82 & 3.1 \\
\hline$S$ Des & 20.3 & 6.1 & 21.7 & 5 & 11.5 & 6.9 & 22 & 5.5 \\
\hline R cont & 8.6 & 1.8 & 8.9 & 1.5 & 8.1 & 2 & 9.2 & 1.6 \\
\hline
\end{tabular}

Note $=$ E stab= Emotional Stability; Anx= Anxiety; S-con $=$ Selfconcept; Effi= Efficacy; S-conf= Self-Confidence; Indep= Independence; Dom= Domination; Cog= Cognitive Control; Sociab= Sociability; S adj: Social Adjustment; Aggre= Aggressiveness; Tol=Tolerance; S Intel= Social Intelligence; Int/Hon=Integrity/Honesty; Lead= Leadership; Sinc= Sincerity; $S$ Des= Social Desirability; $R$ cont= Response Control. 
Table 2. ANOVA 2(groups CG vs. FG) x 2(time 1vs. time 2).

\begin{tabular}{|c|c|c|c|c|c|c|}
\hline & \multicolumn{2}{|c|}{ Group } & \multicolumn{2}{|c|}{ Time $\times$ Group } & \multicolumn{2}{|c|}{ Time } \\
\hline & $\mathrm{F}$ & $\square^{2}$ & $\mathrm{~F}$ & $\square^{2}$ & $\mathrm{~F}$ & $\square^{2}$ \\
\hline E stab & $5.13^{*}$ & .02 & $6.19^{\star \star}$ & .03 & .09 & .00 \\
\hline Anx & 2.38 & .01 & .34 & .00 & $7.62^{\star *}$ & .03 \\
\hline S-con & $138.06^{\star *}$ & .02 & $25.01^{\star \star}$ & .11 & 3.66 & .01 \\
\hline Effi & $79.67^{\star *}$ & .28 & $88.37^{* *}$ & .30 & $68.82^{* *}$ & .25 \\
\hline S-conf & $27.51^{* *}$ & .12 & $49.17^{\star \star}$ & .19 & $20.61^{* *}$ & .09 \\
\hline Indep & $10.66^{\star *}$ & .05 & .37 & .00 & $5.35^{\star}$ & .02 \\
\hline Dom & $59.06^{\star *}$ & .23 & $35.18^{\star \star}$ & .15 & $34.08^{* *}$ & .14 \\
\hline Cog & $119.38^{\star *}$ & .37 & $101.77^{\star *}$ & .34 & $55.05^{* *}$ & .21 \\
\hline Sociab & $13.28^{* *}$ & .06 & $13.03^{* \star}$ & .06 & $9.39^{\star *}$ & .04 \\
\hline$S$ adj & $54.87^{* *}$ & .21 & $23.17^{* \star}$ & .10 & $30.14^{* *}$ & .13 \\
\hline Aggre & $38.49^{* *}$ & .16 & $6.17^{\star}$ & .03 & $14.87^{* *}$ & .07 \\
\hline Tol & $75.48^{\star *}$ & .27 & $36.28^{* *}$ & .15 & $46.53^{\star \star}$ & .19 \\
\hline S Intel & $120.05^{\star *}$ & .37 & $88.9^{\star \star}$ & .31 & $56.41^{* *}$ & .22 \\
\hline Int/Hon & $172.31^{* *}$ & .46 & $128.13^{* *}$ & .39 & $112.66^{\star \star}$ & .36 \\
\hline Lead & $29.33^{* *}$ & .12 & $16.09^{\star \star}$ & .07 & $9.41^{* *}$ & .04 \\
\hline Sinc & $49.33^{\star *}$ & .20 & 30.88 & .13 & $27.94^{\star \star}$ & .12 \\
\hline$S$ Des & $88.38^{* *}$ & .30 & $66.10^{\star *}$ & .25 & $59.51^{* *}$ & .23 \\
\hline$R$ cont & $88.38^{\star *}$ & .30 & $66.01^{* *}$ & .25 & $59.51^{* *}$ & .23 \\
\hline
\end{tabular}

Note= E stab= Emotional Stability; Anx= Anxiety; S-con= Self-concept; Effi= Efficacy; Sconf= Self-Confidence; Indep= Independence; Dom= Domination; Cog= Cognitive Control; Sociab= Sociability; $S$ adj: Social Adjustment; Aggre= Aggressiveness; Tol=Tolerance; S Intel= Social Intelligence; Int/Hon=Integrity/Honesty; Lead= Leadership; Sinc= Sincerity; S Des= Social Desirability; R cont= Response Control. ${ }^{*} \mathrm{p}<.05 ;{ }^{* *} \mathrm{p}<.01$ 
Table 3. Respondents categorized as "reliable"in time 1 and 2.

\begin{tabular}{lllll}
\hline & \multicolumn{2}{c}{ Time 1 } & \multicolumn{2}{c}{ Time 2 } \\
\hline Control scale & FG & CG & FG & CG \\
\hline Sincerity & $78(96.3 \%)$ & $68(84 \%)$ & $73(90.1 \%)$ & $69(85.2 \%)$ \\
Social desirability & $79(97.5 \%)$ & $73(90.1)$ & $78(96.3 \%)$ & $63(77.8)$ \\
Response control & $49(60.5 \%)$ & $65(80.2 \%)$ & $58(71.6 \%)$ & $70(86.4 \%)$ \\
\hline
\end{tabular}


Graphic 1. Efficacy of the fake induction in CPS scales.
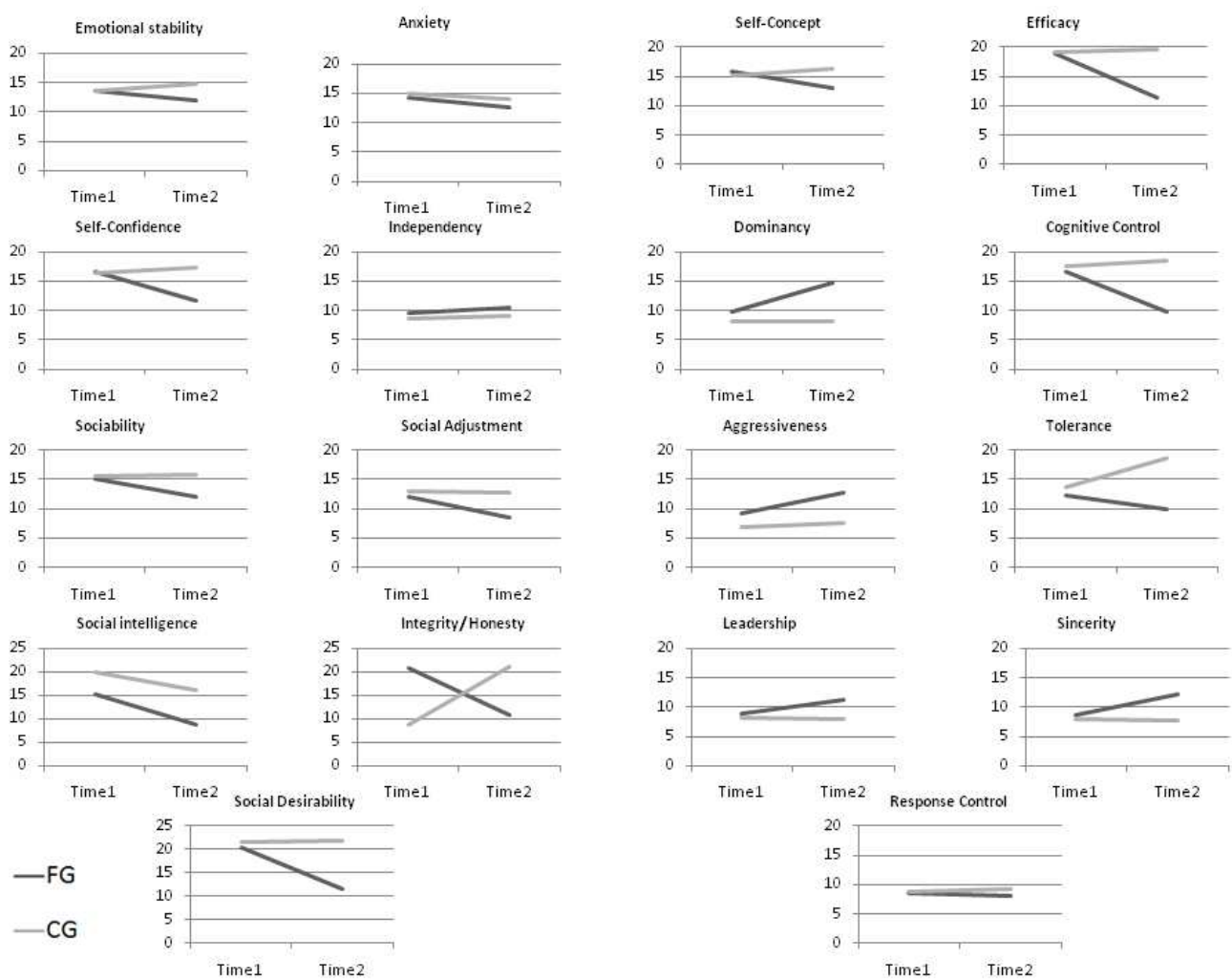

30

31

32

33

34

35

36

37

38

39

40

41

42

43

44

45

46

47

48

49

50

51

52

53

54

55

56

57

58

59

60

URL: http:/mc.manuscriptcentral.com/rjfp Email: forensic-psychiatry@nottingham.ac.uk 

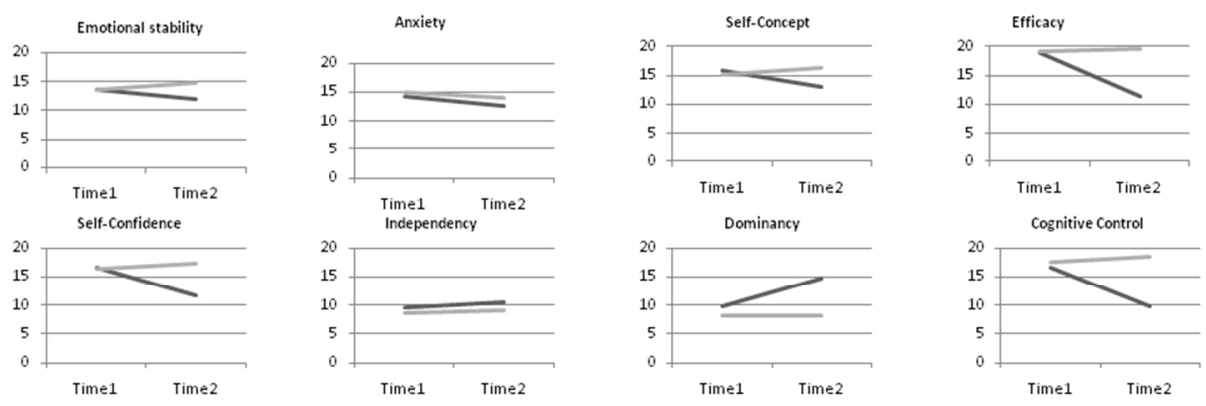

Cognitive Control
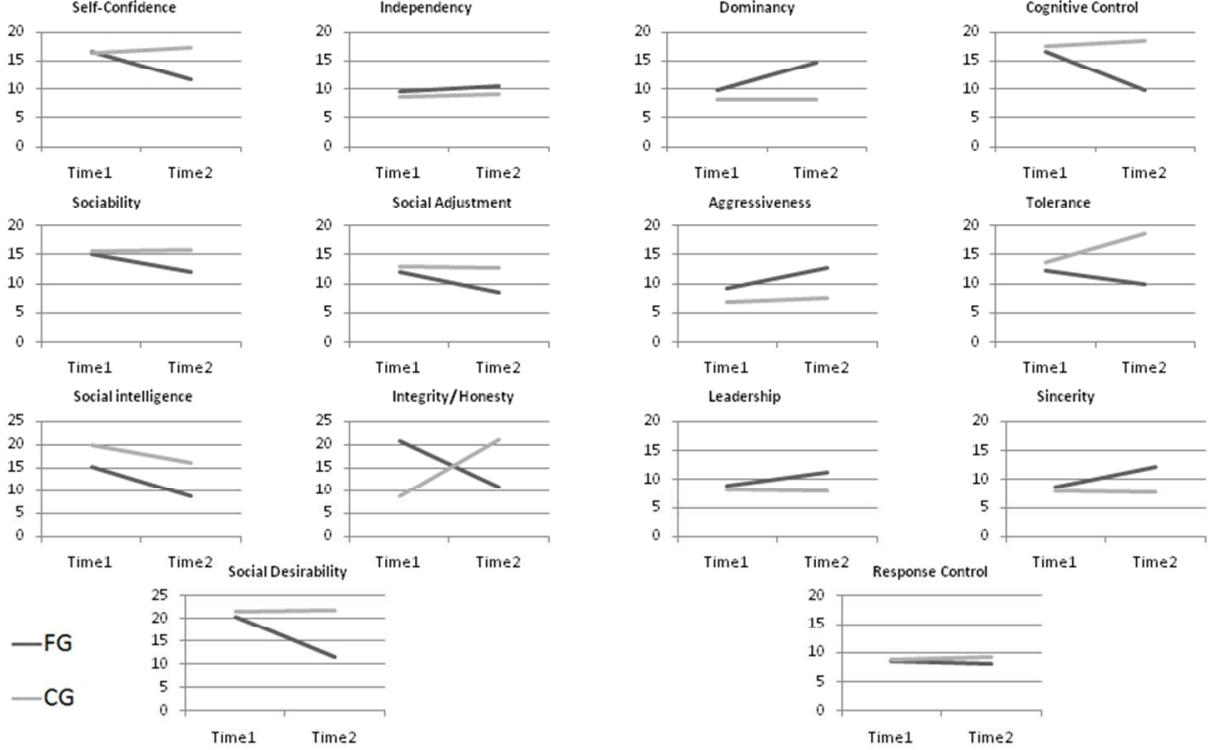

Time1 Time2 Response Control Time1 Time2

$254 \times 190 \mathrm{~mm}(96 \times 96 \mathrm{DPI})$

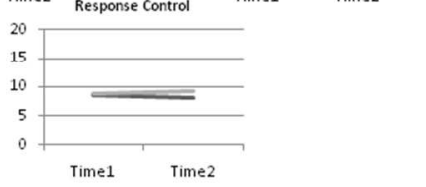

